\author{
Valerija Korošec
}

\title{
Zgodba (predloga) o UTD v Sloveniji in njen kontekst
}

\begin{abstract}
Ključne besede: univerzalni temeljni dohodek (UTD), »industrija revščine«, paradigmatski premik, postindustrijska družba
\end{abstract}

DOI: $10.4312 /$ ars.8.1.188-199

\section{Uvod}

V prispevku bo opisana osebna izkušnja, ki služi kot podlaga za razmislek o tem, zakaj je ideja univerzalnega temeljnega dohodka kot povsem teoretičnega koncepta v knjigah postala raison d'etre organizacije (Sekcije za promocijo UTD v Sloveniji, približno 20 ljudi), njenih mednarodnih povezovanj in akcij ter promocije ideje UTD v slovenski družbi. Promocija v Sloveniji je vključevala tekste, predavanja, posvete (DS) ter sodelovanje v civilnih pobudah in celo vstajah leta 2012/2013. Na mednarodni ravni gre za vključitev v Svetovno mrežo za UTD (BIEN), soorganizacijo oziroma sodelovanje na mednarodni konferenci o UTD, pobude in sodelovanje v Evropski državljanski pobudi ter za odločitev, da poskusi sodelovati na evropskih volitvah 2014 z neodvisno listo UTD. Nekateri zapisi o tem, kako se je to dogajalo, že obstajajo. ${ }^{1}$

A pri poskusu razumevanja delovanja družbe in države, (samo)organiziranosti in (ne)solidarnosti njenih medsebojnih delov je pomembnejši odgovor na vprašanje, zakaj so se stvari dogajale tako, kot so se. Zakaj je predlog uradnice iz vladnega urada RS, ki je predlagala posodobitev dela državnega administrativnega aparata, postal del alternativne družbene organizacije, ne pa del vladnih reform? Zakaj so bili izračuni, ki so dokazovali javnofinančne koristi, diskvalificirani, spregledani in ignorirani - in to $\mathrm{v}$ časih, ko so javnofinančni izdatki eden večjih problemov v državi? Zakaj nekdo, ki skuša narediti vse v skladu s privzgojenimi družbenimi pričakovanji, pristane na »drugi strani« (med alternativci, aktivisti, protestniki, zombiji)? Na ta vprašanja bi morda lahko odgovorila antropološka in feministična analiza tega dogajanja. A največ, kar lahko storim sama, je zapis osebne zgodbe, ki bi lahko kdaj v prihodnosti služil temu namenu. Zato se v pričujočem besedilu »objektivni« zapisi, tj. zapisi, ki jih je mogoče preveriti v objavljenih tekstih, posnetih oddajah in e-pismih, prepletajo $\mathrm{z}$

1 Glej na primer v Taufer, Veno in Kokalj, Nina (2013). Slovenska kultura sredi razpada vrednot: ob Vseslovenski ljudski vstaji / Tribuna Društva slovenskih pisateljev, Cankarjev dom, 31. 1. 2013. Ljubljana: Društvo slovenskih pisateljev, zapis o Sekciji UTD. 
osebnimi reminiscencami, zastranitvami in komentarji. Mislim, da bi predvsem ta del lahko v prihodnosti komu koristil. V tej luči želi ta nadrobni zapis doseči, da se bodo naši nasledniki v ponovitve naših dejanj podali bolje oboroženi $z$ dejstvi in skepso ter z manj naivnosti. Sama skoraj ne morem verjeti lastni naivnosti: da nekatere stvari razumem šele sedaj, pri skoraj petdesetih in po desetih letih ukvarjanja z UTD, pri tem pa je še vedno več vprašanj kot odgovorov. A nekateri izmed bolj presenetljivih odgovorov so se izkristalizirali prav skozi zapisovanje tega teksta - na primer odgovori na vprašanja, ki so me zadnja leta pogosto zasledovala (predvsem pri neuspehih): Sem »kriva« jaz, ne razumem, ne znam, sem preveč čustvena? Ali je »krivo« to, da sem ženska, da sem sociologinja in ne ekonomistka? Ali pa so razlogi sistemski (družbeni) in gre za razredno vprašanje? Gre za vprašanje političnih polov? Gre za problem slovenske družbe? Gre za »napačno« socializacijo oziroma vzgojenost v drugačnem ideološkem sistemu, kot ga živimo sedaj? Gre za problem paradigmatskega premika (po Kuhnu, 1998), ko se vse, kar smo se kdaj naučili in verjeli, postavlja pod vprašaj? Ali je kaj drugega, česar sploh ne znam zaobjeti z vprašanjem?

\section{Prvi zbornik o UTD ${ }^{2}$}

V zgodbo o UTD sem vstopila pred desetimi leti. V službi na Uradu za makroekonomske analize in razvoj (UMAR), Sektor za družbeno blaginjo in socialni razvoj, sem kolegici dejala, da si samo še upokojeni ljudje upajo pisati resnico po svoji glavi in vesti in da se zato v časopisih splača brati samo še pisma bralcev. Zato bi bilo treba vsem v Sloveniji zagotoviti vsaj tolikšno eksistenčno varnost kot upokojencem, da bi lahko ljudje svobodno razpravljali ter si drznili dajati pobude in predloge za izboljšave. ${ }^{3}$ Kolegica mi je čez mizo podala knjigo, rekoč: »Poglej, o tem piše v zborniku Zastonj kosilo za vse (Pribac, 2004), in če te res tako zanima, ga komentiraj v oddaji Knjiga mene briga.« Tako sem se najprej udeležila predstavitve zbornika v Cankarjevem domu in nato skupaj z dr. Darjo Zaviršek oddaje Knjiga mene briga.

Prvi zbornik o UTD iz leta 2004 je prva knjiga v slovenskem prostoru, ki je bila namenjena predstavitvi sodobne različice stare humanistične ideje univerzalnega temeljnega dohodka, tj. dohodka, ki ga brez vseh pogojev prejme vsak član določene (človeške) skupnosti. Za prodor ideje $\mathrm{v}$ družbo in politično sfero pa ni pomembna samo vsebina ideje, njena konsistentnost in uresničljivost, pač pa tudi to, kdo se z njo ukvarja, kdo jo zagovarja in kdo ji nasprotuje (Khahn, 1998). Glede na to, kateri so

2 Pribac, I. (ur.), Zastonj kosilo za vse? Predlog univerzalnega temeljnega dohodka, Ljubljana 2004. V nadaljevanju omenjen kot "prvi zbornik«.

3 Takrat me še ni tako motilo, da ta pisma bralcev piše 99 \% upokojencev in 1 \% upokojenk. Prav tako si takrat nisem mogla predstavljati, kako se bo v desetih letih raven pisanja v Sloveniji spričo njihove in družbene nesvobode znižala. 
bili (ob tujih) slovenski avtorji, je urednik prvega zbornika, dr. Igor Pribac, to nalogo (razen na področju spolne paritete ${ }^{4}$ ) opravil več kot odlično (glej Pribac, 2004). Za začetek debate bi si težko predstavljali bolj eminentna imena ter hkrati tako dobro pokritost najbolj izpostavljenih strok (filozofije, sociologije, ekonomije in politike): dr. Igor Pribac, dr. Srečo Dragoš, dr. Tanja Rener, dr. Jože Mencinger, dr. Janez Šušteršič, mag. Bojan Radej, dr. Milan Zver.

Na predstavitvi knjige pa me je zelo motilo, da ni nihče povedal, kakšno višino UTD imajo v mislih. Vsa debata glede možnih posledic uvedbe UTD je bila zato povsem $\mathrm{v}$ zraku. Povsem logično je namreč, da je za presojo o vplivu UTD na javne finance ali na motivacijo ljudi za delo treba vedeti, o kakšni višini UTD govorimo. Vame pa se je že ob prebiranju knjige zapičila misel, ki se je na predstavitvi samo še dodatno zasidrala in ki sem jo skušala predstaviti že v oddaji Knjiga mene briga. Slovenski socialni sistem temelji na dveh premisah: človek bo za preživetje zaslužil sam, če pa za to (trenutno) (še) ni (več) sposoben, mu bo pomagala družba. To pomeni, da je slovenski sistem v cilju in obljubi že sedaj univerzalen, tj. da tako ali drugače na koncu poskrbi za vse. In če je to res, samo logistične administrativne spremembe ne bi pomenile povečanega obsega finančnih sredstev, ampak $\mathrm{v}$ primeru poenostavitve sistema celo prihranek. Ta cilj bi torej lahko z enakimi sredstvi dosegli s preprostejšim, bolj transparentnim in cenejšim sistemom, ki ga zagotavlja njegova »brezpogojnost«. Brezpogojnost namreč odpravi potrebo po dragem in kompliciranem državnobirokratskem sistemu, ki preverja upravičence. Iz te ideje je zrasel Predlog o UTD v Sloveniji.

\section{Predlog UTD v Sloveniii, zakaj in kako 5}

"Neposredno je nastanek Predloga UTD v Sloveniji spodbudil bodoči finančni minister dr. Franc Križanič, ki je ob ustoličevanju nove vlade konec leta 2008 »obljubil« UTD v višini 500 evrov. Splošni javni odziv je bil nejevera in (medijsko) zasmehovanje ministra kot sanjača. Po drugi strani pa se je v reviji Mladina obudila debata o UTD ..." (Pribac, Korošec, 2011), v kateri sem sodelovala tudi sama. Tako me je poklical g. Branko Gerlič iz Maribora, ki je bil v nadaljevanju glavni pobudnik, organizator in koordinator Sekcije UTD za promocijo UTD v Sloveniji pri Zofijinih ljubimcih v Mariboru. A ena od posledic Križaničeve izjave je bilo tudi dovoljenje direktorja UMAR-ja, da pripravim izračun javnofinančnih posledic uvedbe UTD, če bi Vlada RS takšen izračun kdaj potrebovala.

4 Uradno določeno razmerje med spoloma glede na število predstavnikov enega ali drugega spola $\mathrm{v}$ skupini. Sopomenka: spolno razmerje, a ker ta termin implicira odnos med dvema posameznikoma, raje pariteta. Glej valutna pariteta (»currency parity«): uradno določeno razmerje med vrednostma dveh valut. Sopomenka: valutno razmerje. 
Seveda pa se v debato ne bi mogla vključiti, če se z UTD ne bi ukvarjala od leta 2004 (naročila sem se na spletni časopis Svetovne mreže za uvedbo UTD (BIEN's NewsFlash), prebirala prispevke $\mathrm{z}$ njihovih mednarodnih konference, guglala za članki po svetu in v Sloveniji). ${ }^{6}$ Z UTD se je ukvarjal (nekdanji) direktor institucije, v kateri sem bila zaposlena, z njim so se ukvarjali moji (nekdanji) ${ }^{7}$ akademski kolegi ter kolegi po znanstveni disciplini (sociologi in raziskovalci socialne politike) - na primer dr. Veljko Rus, ki je v knjigi, zaradi katere sem se vpisala na magistrski študij socialne politike, Socialna država in država blaginje (1990), precej natančno opisal idejo univerzalnega temeljnega dohodka, ki ga v knjigi imenuje »minimalni dohodek «.

»Vladna namera radikalnih reform socialne države je bil dodaten impulz za pisanje Predloga UTD. Skušala sem napisati »alternativni program reforme socialne države«, ker sem bila prepričana (in sem še zdaj), da bi bil lahko UTD tisti inovativni in alternativni program reforme socialne države, s katerim bi si ljudje povrnili potreben optimizem, samozavest in zaupanje v prihodnost, Slovenija pa bi si zagotovila stabilen gospodarski razvoj, ki mu mejo določata skrb za ekološko vzdržnost in eksistenčno varnost vseh prebivalcev Slovenije« (ibid.). Predlog UTD je bil zato tako preprost (»ready made«), da bi ga lahko uporabili tako rekoč od »danes na jutri«. In zato ne vsebuje niti večjih posegov v davčni sistem niti v sistem socialne varnosti. Če bi vedela, da bo Predlog UTD moral čakati toliko let, bi napisala »idealnotipski« predlog UTD. Tako pa je po 4 letih razočaranje toliko večje, saj »kritiki« UTD niso sposobni niti dobro argumentirane kritike, kaj šele konkurenčnega predloga. V tistem času sem bila torej prepričana, da je moja aktivnost v skladu $\mathrm{z}$ »duhom časa«, s službenimi in družbenimi pričakovanji, kot so mi jih predstavili oziroma kot sem jih razumela: o nenehnem (samo)izobraževanju, strokovnem izpopolnjevanju, samoiniciativnosti, družbeni aktivnosti itd. Nikoli nisem bila upornica, pač pa "pridna punca«. Zakaj nekdo, ki skuša narediti vse v skladu z družbenimi pričakovanji, pristane na »drugi strani«? Ali je to tipični slovenski sindrom? Konec koncev je tudi dr. Pučnik pristal v zaporu zato, ker je predlagal izboljšavo sistema.

\section{Predlog UTD znotraj državne uprave}

Ob interni predstavitvi delovne verzije (po eni strani bolj enostavne, po drugi strani pa bolj komplicirane) so sodelavci na UMAR-ju (večinoma »mainstream» ekonomisti) vse skupaj (idejo in izvedbo) pretežno in odkrito zavrnili. Dva komentarja sta bila zelo povedna in zanimiva. Prvi sodelavec: "Ali mislite, da lahko družbeni

6 Na primer Uroš Boltin v gibanju za Pravičnost in razvoj, ki ga je ustanovil pokojni predsednik RS Janez Drnovšek, kjer idejo UTD podpirajo.

7 Preden sem se zaposlila na UMAR-ju, sem bila sedem let zaposlena na Pedagoški fakulteti v Mariboru na Oddelku za sociologijo. 
sistem spremenimo z zakonom? « Takrat in še posebej v tistem okolju nisem bila dovolj samozavestna, da bi to temo razvijala naprej, a res je tako: mislim, da se narava družbenega sistema spreminja točno tako, $\mathrm{z}$ zakoni. ${ }^{8} \mathrm{~A}$ iz te pripombe je bilo razvidno, da so pazljivi poslušalci že na tej predstavitvi uvideli, da UTD spreminja sedanjo (kapitalistično, neoliberalno) naravo družbenega sistema, pa tudi to, da ti poslušalci o njegovem preseganju nočejo razmišljati, ker so z obstoječim sistemom zadovoljni, ter da večina ostalih o tem ne zna ali si ne upa razmišljati. Drugi sodelavec: »V Sloveniji sistem, ki zahteva tolikšno redistribucijo, ne bo nikoli sprejet.« Moj odgovor je bil: »To je sistem za hude čase. Ko bo tako hudo, kot je bilo po drugi svetovni vojni, ko bodo ljudje razumeli, da morajo najprej poskrbeti za eksistenčni minimum vseh, bo to možno. In mislim, da bo še zelo hudo. Zato je dobro imeti tak sistem pripravljen in premišljen vnaprej, za vsak primer. « Morda velja bralca opomniti, da sem o »krizi«, ki bo spominjala na povojni čas, ${ }^{9}$ govorila v času, ko se v Sloveniji »krize« uradno sploh še ni priznalo, kaj šele dojelo, za kaj gre. To sicer traja še zdaj. Oblastniki v tej državi, tj. »t. i. elita«, še po 6 letih ne razumejo (ali se delajo, da ne razumejo), da gre za paradigmatski premik (epohalni prehod), prehod iz industrijske (moderne) $\mathrm{v}$ postindustrijsko (postmoderno) družbo $\mathrm{v}$ času globalizma in skrajnih okoljskih neravnovesij; da so tu razlogi »kriz«: finančne, gospodarske, politične, socialne, vrednotne, etične itd.; da je treba v družbi, kjer je »pridnost za delo« sidro vrednotnega sistema, to delo pa čedalje bolj nadomešča tehnologija, konkurenca iz tujine ali pomanjkanje virov, s tem »mankom» v mislih vrednotni sistem »zasidrati« drugače.

Po recenziji dr. Mencingerja, ki sem ga kot recenzenta predlagala jaz, in dr. Janeza Šušteršiča, ki ga je predlagal UMAR, sem oblikovala končno verzijo, v katero sem vključila tudi zahtevo po finančni nevtralnosti uvedbe UTD, in sicer zato, da ne bi mogel Predlogu nihče ugovarjati z argumentom, da si UTD v teh kriznih časih »ne moremo privoščiti ${ }^{10}{ }^{10}$ In kljub temu je to še vedno glavni argument vseh javnih debat - tudi zato, ker lahko na prste preštejem ljudi, ki so prebrali Predlog ali drugi zbornik o UTD: UTD v Sloveniji (Pribac, Korošec, 2011).

Na Dnevih javne uprave (144 vabljenih) so me poslušali ljudje iz davčne uprave, MNZ, občinskih uprav itd. Tako rekoč prvič in zadnjič sem imela občutek, da sem govorila ljudem, ki so razumeli izračune o uvedbi UTD. In ko so po predstavitvi k meni pristopile ženske (med poslušalci so bile seveda v večini, kar je za feminizirano

8 Recimo z zakoni o nacionalizaciji, o denacionalizaciji (v naravi), zakonom o skupni, družbeni ali osebni lastnini.

9 Ne vem, ali sem pretiravala ali samo še nismo tam.

10 Javnofinančno vzdržnost predlaganega sistema UTD je leta 2013 v svoji diplomski nalogi Univerzalni temeljni dohodek (str. 42) do določene mere potrdil Luka Fajfar (slabost tega izračuna je v pomanjkanju izračuna dodatnih davčnih virov financiranja UTD - to pa lahko izračuna samo Ministrstvo za finance). 
javno upravo običajno) in rekle, »da je po več kot 20 letih dela $\mathrm{v}$ javni upravi to prvi predlog reforme, za katerega so slišale, $s$ katerim bi lahko dejansko zmanjšali administracijo in stroške«, sem bila še bolj prepričana, da sem na pravi poti in da je povsem logično pričakovati, da lahko na osnovi nadaljnjih raziskav (na primer inštituta IER, ministrstva) pričakujemo, da bodo koncept UTD vsaj malo upoštevali tudi $\mathrm{v}$ načrtovani reformi socialnega sistema. Tako sem izjemno hvaležna dr. Marjanu Majcnu in dr. Nataši Kump, ki sta na Inštitutu za ekonomska raziskovanja decembra $2011 \mathrm{iz}$ čiste znanstvene radovednosti zavrtela mikrosimulacijski model z upoštevanjem Predloga UTD. Na ta način sem dobila izračun in primerjavo posledic uvedbe UTD glede javnofinančnih sredstev, dohodkovne razporeditve po decilih in po izbranih socio-ekonomskih skupinah, ki je omogočil primerjavo s starim sistemom ter $\mathrm{z}$ načrtovano Svetlikovo reformo. A na interni predstavitvi rezultatov ni bilo nikogar od vabljenih strokovnjakov, nikogar, ki bi dobljene rezultate sploh razumel, kaj šele kritiziral! Zato še danes ne vem, koliko so ti - sicer pozitivni - rezultati veljavni. A nisem in nisem mogla razumeti, kako je mogoče $\mathrm{v}$ časih, ko se najbolj poudarjajo problemi javnih financ in revščine, tako idejo ignorirati. In že če bi ideja prinesla samo polovico tistega, kar obljublja, bi jo bilo vredno preveriti. A prav letos (2014) mi je na izobraževanju o najnovejših aplikacijah evropskih mikrosimulacijskih modelov dr. Majcen govoril o izkušnji iz tistega časa, ko so za dr. Svetlika (takratnega ministra za delo, družino in socialne zadeve) preračunavali učinke reform, v zakon pa so se zapisovale stvari povsem mimo tistih izračunov. Gre za občutek, ki ga je marca 2014 na poslovilni zabavi izrazila tudi moja šefica L. A. V.: »... za občutek, da gredo ne glede na zavzeto in strokovno delo stvari povsem svojo pot.« Po toliko letih si torej lahko rečem, da pri spregledovanju in ignoriranju verjetno ne gre (nujno) za »osebni problem«. Tudi večji strokovnjaki so bili s strani »države« podobno ignorirani in spregledani. A kdo je tu »država«? Državni aparat, za katerega bi morale biti izboljšave oziroma posodobitve "upgrading «, "updating «) sistema samoumevne? Seveda tudi v svetu govorijo o rigidnosti velikih sistemov, o "path dependancy«, a človek se kljub temu sprašuje, ali ne gre v Sloveniji za skrajno obliko tega pojava. Ali je razlog v politični sferi? V slovenskih političnih polih? Od kod tolikšna rigidnost sistema? Zakaj je tako?

\section{Predlog UTD in politična sfera}

Dolgo nisem mogla razumeti, kako da Predlog UTD ne zbudi večjega zanimanja pri g. Gregorju Golobiču, takratnem šolskem ministru in predsedniku stranke Zares, stranke, ki je imela UTD v svojem programu, ali pri dr. Svetliku, mojem mentorju z magistrskega študija, takratnem ministru MDDSZ ter profesorju, ki je študentom FDV predaval o UTD. Oba sta bila ministra v Pahorjevi socialdemokratski vladi. Sedeč poleg njiju sem govorila o Predlogu. Oba sta reagirala enako. V medijih (do katerih 
sem sama imela omejen dostop) sta Predlog »diskvalificirala s s potvarjanjem dejstev (trdila sta na primer, da je predlagani UTD prenizek in da bi bili ljudje na slabšem kot v obstoječem sistemu). To ni res. Pa četudi bi bilo res, je zanimivo, zakaj sta ga diskvalificirala, namesto da bi predlagala skupno iskanje boljše rešitve, glede na to, da je Predlog UTD enega ministra zadeval zato, ker je bil v programu njegove stranke, drugega pa zato, ker se je dotikal področja njegovega dela. Bila sem pravzaprav njuna uslužbenka, uslužbenka vlade. Sčasoma sem si stvari razložila tako: če bi bili samo združba "nezadovoljnih« ljudi, če bi pred gledalce prišli s srce parajočimi zgodbami o neučinkovitosti sedanjega socialnega sistema, ki jih je polna oddaja Tednik, bi nas verjetno blagohotno poslušala in obljubila rešitev. (Marsikateri zagovornik UTD misli, da ni naloga civilne družbe predlagati rešitve, pač pa jih od ustreznih organov zahtevati.) Toda takrat je, vsaj tako sem razumela, ustrezni organ (strokovnjakinja na UMAR-ju) to storil, še preden je to od oblastnikov zahtevala civilna družba in še preden so to od nas strokovnjakov zahtevali oblastniki. In kaj se je tu zgodilo? »Predlog« jim je vzel manevrski prostor za izgovore in za vpisovanje lastnih "političnih« rešitev. Šlo je za »Predlog«, ki je temeljil izključno na strokovnih argumentih brez trohice »politike«. Tako smo oblastnike »po pomoti«, ker smo verjeli njihovim zgodbicam (strankarskim programom in političnim obljubam), pritisnili v kot in jih prisilili, da so pokazali svojo pravo naravo, da so samo neverodostojni prodajalci upanja za prihodnost. To je tisto, česar zaradi svoje naivnosti dolgo nisem razumela. In če se ob načinu diskvalifikacije še vedno sprašujem, ali je šlo za statusni problem ali za to, da sta moška, za strukturno vprašanje elit ali za vprašanje »političnega pola«, se je vsaj glede zadnjega vprašanja v zadnjih letih izkristaliziralo, da med političnimi poli v ignoranci do Predloga UTD ni razlike. ${ }^{11}$

\section{Predlog UTD, strokovna javnost in »industrija revščine«}

Predlog UTD sem s prošnjo po kritičnem branju poslala nekaterim svojim kolegom sociologom in ekonomistom, zaposlenim na inštitutih in univerzi, s katerimi si delim področje dela. To prošnjo sem izrekla tudi javno, ko se je dokaj velika skupina sociologov v gostilni Sedmica v Ljubljani zbrala na pogovoru o tem, kako bi sociologi lahko pomagali v času krize. Nič. Od nikogar.

Predlog sem predstavila tudi Uradu varuhinje za človekove pravice (tja me je povabila varuhinja, ki me je poslušala na posvetu v državnem svetu, ${ }^{12}$ a je bila ob

11 Po raziskavi Politbarometra (2013) t. i. levi vedo, kaj UTD je, t. i. desni pa ne. A v praktičnem odnosu do (Predloga o) UTD med vladami Janše, Pahorja, Janše in Bratuškove ni razlike, kot je bilo povzeto v vstajniškem letu: levi ali desni, vsi so isti. V primeru Predloga UTD je to res.

12 Posvet v državnem svetu na temo UTD: UTD v Sloveniji - utopija ali realna možnost?, 8. 12. 2010, http://www.zofijini.net/oko_posvet.html [5. 4. 2014] 
tisti priložnosti službeno odsotna). Presenečeno sem ugotovila, da sem imela enak občutek zavračanja kot na UMAR-ju. Kako je to mogoče? Med ljudmi, ki se ukvarjajo s pomočjo ljudem, bi moral koncept UTD kot ultimativno koristna zadeva za dobrobit njihovih klientov vendar zbuditi navdušenje. Na izobraževanju o integriteti in korupciji $\mathrm{v}$ javnem sektorju na KPK sem izpostavila dejstvo, da lahko samo neprestrašen in zaradi UTD opolnomočen in avtonomen človek reče ne koruptivnim poslom oziroma se upre korumpiranim »šefom «. No, tudi tam enako: nevesel sprejem. Tako sem počasi dojemala, kako močan odpor do UTD prevladuje med ljudmi, ki živijo od »industrije revščine«.

... namesto da bi država kaj naredila $\mathrm{v}$ tej smeri, je $\mathrm{v}$ odgovoru napisala: »Uvedba UTD bi pomenila ukinitev obstoječega sistema socialne varnosti $\mathrm{z}$ vsemi koncepti, tradicijo in izkušnjami, na katerih je sistem zgrajen. Res je, da je socialni sistem (sistem socialne varnosti), kakršnega v različnih izpeljavah poznamo $\mathrm{v}$ Evropi, tarča različnih kritik (na primer glede njegove učinkovitosti, kompleksnosti, velikega administrativnega aparata, ki ga potrebuje za delovanje in ki, mimogrede, predstavlja delovna mesta) ...« Delujoča država bi morala sama izboljševati lastni sistem, ne pa da moramo za spremembo tega okostenelega, korumpiranega, tj. nedelujočega in neučinkovitega režima zbrati milijon podpisov, da se bo sploh začelo z raziskovanjem drugačnih možnosti! Marsikomu se zdi UTD upravičeno primerjati s cepljenjem proti strahu ... Kako pa mislite, da bi zdravniški ali farmacevtski lobiji reagirali na domače naravno zdravilo, ki bi jim odpihnilo dobičke? Enako se na idejo UTD odziva »industrija revščine«, tj. vsi, ki živijo na račun osiromašenega drugega, in vsi, ki se bojijo opolnomočenih in emancipiranih ljudi (Taufer, Kokalj, 2013). ${ }^{13}$

O učinku »debirokratizacije« sistema zaradi uvedbe UTD sem pisala od začetka ukvarjanja z UTD - o učinku eksistencialnega strahu ob grožnji izgube službe prav tako. Kljub temu pa sem zelo naivno menila, a) da bodo "prizadeti« strokovnjaki v okviru državne oziroma znanstvene »birokracije» ta strah sposobni preseči zaradi širših in dolgoročnih koristi (prihodnost njihovih otrok in skupnosti) in b) da bodo drugi, "neogroženi« strokovnjaki znali presojati »objektivno«, na podlagi dejstev, argumentov in številčnih izračunov. Motila sem se v obeh oziroma vseh pogledih. Eksistenčni strah in strah pred izgubo statusa sta premočna. Zato ljudje, ki so sposobni Predlog oceniti in preveriti, tega nočejo storiti, ker jih UTD ogroža. Drugi, ki jih UTD ne ogroža neposredno, pa za to niso usposobljeni. In ne samo to. Celo pri zagovornikih UTD se lahko sprašujemo o iskrenosti njihove želje po uvedbi UTD. O čem bo(m)o pa potem pisali, organizirali konference, govorili in sanjali? In tako na

13 Glej tudi: Portal predlagam.vladi.si, Predlog UTD, http://predlagam.vladi.si/webroot/idea/view/2130. 
vse strani dvomiš v namen, motive in etičnost ljudi, ki sodelujejo(mo) v industriji revščine in debati o UTD. Sčasoma se je izkristalizirala ugotovitev o nesolidarnosti t. i. elit: ne zanimata jih reševanje družbenih problemov in solidarnost do ranljivih, pač pa parcialne koristi elit, ki jih imajo, če problema ne rešijo. To so strokovnjaki, ki imajo posredne ali neposredne koristi od »industrije revščine« oziroma boja proti revščini. V določenem smislu so to vsi, ki živijo od tega, da "pomagajo revežem «. Na to lahko pogledamo tudi širše. V tem trenutku vsi živimo v družbi, kjer prevladujejo storitvene dejavnosti, kar pomeni, da večina ljudi živi od »prodajanja storitev« ljudem, ki jih potrebuje(mo)jo. Velikokrat potrebuje(mo)jo pomoč. Živimo torej v družbi, kjer večina ljudi živi na način »izkoriščanja človeka po človeku« oziroma "pomoči sočloveku«. Vse skupaj, od državnega aparata do različnih prostovoljnih organizacij, celo družinskih institucij, lahko vidimo kot »neke vrste industrijo revščine«. Toda zakaj se zdi, da je ta soodvisnost ljudi problem in ne rešitev? In zakaj se zdi, da je ta problem večji v Sloveniji kot drugje?

\section{Zaključek}

In potem pridem do vedno istega odgovora: razlog, da je naša soodvisnost problem in ne rešitev, je $\mathrm{v}$ eksistencialnem strahu, ki je $\mathrm{v}$ osrčju sedanjega družbenega sistema; strahu posameznika, ki izvira iz tesne vpetosti človeka - v tem kompleksnem svetu soodvisnosti - v družbene vezi, tako da sprememba sistema prinaša eksistencialno (statusno) ogroženost. In to velja tako za strokovnjake $\mathrm{v}$ industriji revščine kot za delavce, ki hodijo v službo, četudi niso plačani. Velja za vse prekerno zaposlene (tudi visoko izobražene, kreativne, intelektualne) ljudi, ki imajo zakon na svoji strani, ki bi si lahko celo iztožili poštene delovne pogoje, pa si ne upajo iti "proti sistemu«. Velja za vse zaposlene ljudi. In vedno znova pridem do iste rešitve: to vpetost, ujetost $\mathrm{v}$ ta samodestruktivni in rigidni sistem lahko razreši samo univerzalni, brezpogojni, individualizirani temeljni dohodek, ki ljudi osvobodi vsaj toliko kot upokojence. Tako si bodo upali izvesti nujne sistemske spremembe, ki jih v času globalizma in okoljskih neravnovesij zahteva prehod $\mathrm{v}$ postindustrijsko družbo. Tako zaradi novih pristopov, idej in poslovnega tveganja ne bodo ogrožali eksistence svojih bližnjih. Sicer je spričo majhnosti Slovenije vsak "upornik " prisiljen emigrirati, omrtvičenost in rigidnost v sistemu pa se samo še večata. Emigrira lahko v tujino ali na »drugo stran«, med alternativce, protestnike in zombije - tako kot je Predlog UTD iz strokovno raziskovalne in akademske sfere in iz navadnega predloga za izboljšavo sistema razdeljevanja pravic iz javnih sredstev postal alternativna, "utopična ideja, jaz pa iz strokovnjakinje aktivistka. In ideja UTD bo ostala utopična tako dolgo, dokler se s pridobivanjem politične in medijske moči ne bo - hkrati z drugimi nujnimi paradigmatskimi spremembami - 
vzpostavila kot hegemona paradigma nove dobe. To zgodbo pa piše Sekcija UTD pri Zofijinih ljubimcih - s svojimi mednarodnimi povezovanji in promocijo ideje UTD $\mathrm{v}$ slovenski družbi.

\section{Literatura}

Fajfar, L., Univerzalni temeljni dohodek. Diplomsko delo, Univerza v Mariboru, 2013.

Korošec, V., Predlog UTD v Sloveniji - Zakaj in kako?, UMAR, Ljubljana 2010, http://www.umar.gov.si/publikacije/single/publikacija/zapisi/valerija korosec_predlog_utd_v_sloveniji_zakaj_in_kako/5/?cHash=300ae3c4ca\&tx_ ttnews\%5Bsyear\%5D=2010 [10. 4. 2014].

Kuhn, T., Struktura znanstvenih revolucij, Ljubljana 1998.

Portal predlagam.vladi.si, Predlog UTD, http://predlagam.vladi.si/webroot/idea/ view/2130 [10. 4. 2014].

Pribac, I., Korošec, V. (ur.), UTD v Sloveniji - Premisleki, stališča, dokumenti, Ljubljana 2011.

Pribac, I. (ur.), Zastonj kosilo za vse? Predlog univerzalnega temeljnega dohodka, Ljubljana 2004.

Taufer, V., Kokalj, N., Slovenska kultura sredi razpada vrednot: ob vseslovenski ljudski vstaji, Ljubljana 2013. 


\section{Valerija Korošec}

\section{Zgodba (predloga) o UTD v Sloveniji in njen kontekst}

Ključne besede: univerzalni temeljni dohodek (UTD), »industrija revščine«, paradigmatski premik, postindustrijska družba

V prispevku je opisana osebna izkušnja, ki služi kot podlaga za razmislek o tem, zakaj je ideja univerzalnega temeljnega dohodka iz povsem teoretičnega koncepta $\mathrm{v}$ knjigah in predloga uradnice za izboljšavo sistema socialne varnosti postala raison d'etre organizacije (Sekcije za promocijo UTD v Sloveniji, približno 20 ljudi). Za razumevanje tega služi opis konteksta razvoja ideje in (Predloga o) univerzalnem temeljnem dohodku (UTD) v Sloveniji: službeno okolje vladnega urada, državni aparat, strokovna sredina, univerzitetno okolje, politična sfera in njihovi odzivi na idejo univerzalnega temeljnega dohodka. Pri poskusu razumevanja delovanja države in (civilne) družbe $\mathrm{v}$ času paradigmatskega prehoda iz industrijske $\mathrm{v}$ postindustrijsko družbo je pomembno vedeti, zakaj so se stvari zgodile tako, kot so se. 


\section{Valerija Korošec}

\section{The Basic Income (Proposal) Story and Its Context in Slovenia}

Keywords: basic income, poverty industry, paradigm shift, post-industrial society

A story of a personal experience serves as a basis for reflection on why has the idea of a universal basic income has become the raison d'être of the organization Section for the Promotion of UBI in Slovenia (of about 20 people), its international alliances and actions, as well as the promotion of the Basic Income idea within the Slovenian society. Serving this aim is the description of the context of Basic Income idea development in terms of government office, state administration, university, the poverty industry and politics. In trying to understand the functioning of the society (state, civil society) during the paradigmatic shift from industrial to post-industrial society we have to understand why things happen the way they happen. 